UCRL-ID- 120381

\title{
Medical Imaging with Coded Apertures
}

Eric Keto and Stephen Libby

June 16, 1995

This is an informal report intended primarily for internal or limited external distribution. The opinions and conclusions stated are those of the author and may or may not be those of the Laboratory.

W'ork performed under the auspices of the U.S. Department of Energy by the Lawrence Livermore National Laboratory under Contract W-7405-ENG-48.

RECEIVED

AUG 041995

OSTI

DISTRIBUTION OF THIS DOCUMENT IS UNLIMTED 


\section{DISCLAIMER}

This report was prepared as an account of work sponsored by an agency of the United States Government. Neither the United States Government nor any agency thereof, nor any of their employees, make any warranty, express or implied, or assumes any legal liability or responsibility for the accuracy, completeness, or usefulness of any information, apparatus, product, or process disciosed, or represents that its use would not infringe privately owned rights. Reference herein to any specific commercial product, process, or service by trade name, trademark, manufacturer, or otherwise does not necessarily constitute or imply its endorsement, recommendation, or favoring by the United States Government or any agency thereof. The views and opinions of authors expressed herein do not necessarily state or reflect those of the United States Government or any agency thereof. 


\section{DISCLAIMER}

Portions of this document may be illegible in electronic image products. Images are produced from the best available original document. 
Title: Medical Imaging with Coded Apertures

P.I: Eric Keto and Stephen Libby

LDRD Tracking Code: 93SR064

\section{Absuact}

We investigated new algorithms for image reconsuruction in emiscion tomography which could incorporate complex instrumental effects such as might be obtained with a coded

- aperaure system. Orr investigation focused on possible uses of the wravelet transform to handle non-stationary instrumental effects and andytic continuation of the Radon stitransform to handle self-absomption. Neilher investigation was completed during the funding period and whether such algorithms will be useful remains an open question. Introduction

Emission tomography involves the reconstruction of an object from its own internally emitted radiation In medicine, emission tomography is ased to determine the volume density ofan injected radioactive pharmaceutical by measuring the flux of gamma rays emitted in all angles around the patient. Such studies measure biochemical function or metabolism in specific organs such as the heart. Emission tomography is distinguished from transmission tomography which uses an oxternal source of penetrating radiation ustually $x$-rays primarily to determine stracture.

Tomographic reconstructions, both emission and transmission, are performed with the Radon transform, an invertible transform which allows the reconstruction of a function from its projections or line integrals. Howrever, in real tomographic systems, the collected data are only approximations of line integrals in two significant ways. First, no instrument has a perfect. response so that a realistic forward transform would include a convolution of the projection with the response function of the instrament second, in emission tomography, the object both emits and absoms radiation so that the correct integral in the transform is not a simple projection, but the radiative transfer integral. These two difficulties place significant constraints on the design of imaging systems and the interpretation of data. Understanding the Radon transform in greater generality would allow a significant improveraent in imaging capability. The mathematical techniques developed would be equally useful in the 30 imaging of any volume emitter of radiation, for example, a medical patient, a plasma, or radioactive material.

\section{Results}

In this project wo identified two promising techniques for addressing these two problems. The first uses wavelet transforms which are appropriate for deconvolution in precisely such cases as tomography where the instrument response varies across the image (Beylkin, Coifman, and Rokhlin, 1991). Our investigation found that because the Radon transform is not diagoally dominant, the standard technique of wavelet based compression could not $\mathrm{b}$ applied. Horwover, there are a number of approaches that have appeared in the literature from investigations at other institutions conteraporaneous with ours (Bhatia, Karl, and Willsky 1994, Donobo 1994). None of these secans to offer significant advantages over standard inversion techniques. The central difficulty appears to be that the back-projection part of the inverse Radon transform is an cxpansive operator. Still this area of research seems promising. 
As for our second problem we showed that the Radon transform formalism can be maintained even when considering the full radiative transfer equation in place of the line integral if the standard Ralon transform is analyticalty continued to complex arguments. 'Inversion of this transform is then an exercise in complex integration. The integration may be perfomed along certain paths, some of which have been derived in the literature by other methods (Bellini et al. 1979). A general formula for the complex integration is difficult to derive because of essential singularities arising from the geometry of the Radon transform itself. For example, define two coordinate systems, one rotated by angle $\phi$,

$$
\begin{aligned}
& \xi=x \cos \phi+y \sin \phi \\
& \eta=x \sin \phi+y \cos \phi
\end{aligned}
$$

Then an attemusted projection is defined as

$$
p(\xi, \eta)=\int_{-\infty}^{+\infty} f(\xi, \eta) e^{-\alpha \eta \eta} d \eta
$$

.. .... where $\alpha$ is a constant attenuation coefficient. Taking a one dimensonal Fourier transform of the projection,

$$
P(k, \phi)=\iint f(\xi, \eta) e^{-2 x(k \xi-1 \alpha \eta)} d \xi d \eta
$$

define complex numbers,

$$
\begin{aligned}
& \lambda_{x}=k \cos \phi+\frac{i a}{2 \pi} \sin \phi \\
& \lambda_{y}=k \sin \phi-\frac{i a}{2 \pi} \cos \phi
\end{aligned}
$$

Formally, f may be rccovered as an inverse complex Fourier tansform, that is a path integral along some specified path. If we choose the path as the real axes of, $\lambda_{x} \lambda_{y}$ then solving for $k$ and $\phi$, we recover the inversion formula from Bellini et al (1979). In this case, $\phi$, is a complex number and a further analytic continuation is necessary: if $\mathrm{k}$ and $\phi$ are to be real numbers, then a possible path is,

$$
\begin{aligned}
& \lambda_{x}=t_{1}+\frac{i \alpha \alpha_{2}}{2 \pi t} \\
& \lambda_{y}=t_{1}-\frac{i \alpha t_{2}}{2 \pi t}
\end{aligned}
$$

where $t=\sqrt{t_{1}^{2}+t_{2}^{2}}$. But at the origin this path is not analyticby virtuc of an essential singularity. Perhaps an extension to higher dimensions would prove fruitful.

Further work is reeded on these techniques and other fast algorithms to fully take arivantage of the advanced capabilities of the next generation of medical imaging systems.

\section{REFERENCES}

Bellini, S., Piacentini, M., Cafforio, C., Rocca, F. 1979, Compensation of tissue absorption in emission tomography, IEEE Trans. ASSP-27(3), 213-218 Bhatia, M., Karl, W.C. and Willsky, A.S. 1994, A Wavelet based method for multiscale tomographic teconstruction, MTT Tech. Rept. LIDS-P-2182, subm. IEEE Trans. Medical lmaging 


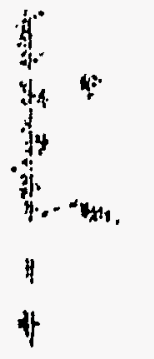

O. Beylkin, R. Coifman, Y. Rokhlin; 1991, Fast wavelet transfoms and numerical algorithms, Comm, Fune and Applied Math, 44, pg. 141 Brooks and deChiro, 1976, Physics in Medicine and Biology, 21, pg. 689 Donoho, $\mathrm{D} 1994$ Non-linear solution of linear inverse problems by Wavelet-Vaguelette Decomposition, Stanford University 